Relations industrielles

Industrial Relations

\title{
R.P. L. BROUWERS, S.J., La doctrine sociale de l'Église et l'entreprise, brochure, 12 pp.
}

\section{Gérard Dion}

Volume 7, numéro 1-2, décembre 1951, mars 1952

URI : https://id.erudit.org/iderudit/1023083ar

DOI : https://doi.org/10.7202/1023083ar

Aller au sommaire du numéro

Éditeur(s)

Département des relations industrielles de l’Université Laval

ISSN

0034-379X (imprimé)

1703-8138 (numérique)

Découvrir la revue

Citer ce compte rendu

Dion, G. (1951). Compte rendu de [R.P. L. BROUWERS, S.J., La doctrine sociale de l'Église et l'entreprise, brochure, 12 pp.] Relations industrielles / Industrial Relations, 7(1-2), 66-66. https://doi.org/10.7202/1023083ar

Tous droits réservés (C Département des relations industrielles de l’Université Laval, 1952
Ce document est protégé par la loi sur le droit d'auteur. L’utilisation des services d'Érudit (y compris la reproduction) est assujettie à sa politique d'utilisation que vous pouvez consulter en ligne.

https://apropos.erudit.org/fr/usagers/politique-dutilisation/ 


\section{LIVRES et REVUES}

\section{ENTREPRISE PRIVEE}

De tous les groupements patronaux d'inspiration catholique, l'Association des Patrons et Industriels chrétiens de Belgique (APIC) est sûrement un des plus progressifs. A son dernier congrès annuel tenu à Anvers les 5 et 6 mai 1951, l'APIC avait pris comme thème l'Entreprise privée. Les deux brochures dont la recension suit contiennent le texte des communications qui $y$ ont été présentées.

\section{R.P. L. Brouwers, s.J., La doctrine sociale de l'Eglise et l'entreprise, brochure 12 pp.}

Le titre de l'étude du R.P. Brouwers nous laissait espérer davantage. L'auteur, après ure brève présentation, aborde successivement, en regard avec les enseignements pontificaux, le capital dans l'entreprise, le travail dans l'entreprise et la direction dans l'entreprise. Il cite abondamment et avec beaucoup d'à-propos des textes de Léon XIII, de Pie XI et surtout de Pie XII. Les interprétations qu'il en donne sont généralement acceptables, encore pourrait-on peut-être lui demander plus de précisions. On regrette cependant que l'auteur n'ait pas manifesté une connaissance plus grande de la sociologie de l'entreprise. Affirmer au point de départ que ologiquement l'entreprise se présente avant tout à nous comme un bien est trop simple et trop facile pour être satisfaisant.

Enfip, toute cette étude semble avoir été faite dans une perspective que l'auteur nous découvre en terminant: \&Nous entendons parfois dans des milieux patronaux nonchrétiens, des voix qui s'élèvent, qui témoignent d'une certaine inquiétude à la vue de la menace qui pèse sur leurs droits, qui expriment le désir de voir se réunir plus étroitement tous les patrons pour la défense de ces droits menacés. Mais pareille union n'est possible que sur une base doctrinale. Or cette doctrine indispensable... la voici toute prête. Elle est offerte par l'Eglise non seulement à ses enfants - auxquels elle est d'ailleurs imposée mais également à tous les hommes de bonne volonté ». Nous croyons qu'une telle perspective n'est pas sans comporter quelques périls, car, dans tous les milieux il y a une tendance à vouloir inféoder l'Eglise à des formes temporelles et à exploiter sa doctrine pour des fins profanes.

Le travail du R.P. Brouwers évite cet écueil et malgré les quelques restrictions que nous avons exprimées, il vaut la peine d'être lu. Il rendra sûrement des services, à condition qu'on ne le prenne pas comme une oeuvre définitive.

Georges Henry, Comment maintenir le caractère privé de l'entreprise tout en réalisant lintégration des travailleurs, brochure $16 \mathrm{pp}$., Association des Patrons et Ingénieurs catholiques, 17, rue du Gouvernement Provisoire, Bruxelles.

Georges Henry est membre du Conseil d'administration de l'APIC. Son étude débute par un vibrant appel au réalisme fait aux patrons. Après avoir cité la phrase célèbre de Lacordaire: «C'est le propre des grands coeurs de découvrir le principal besoin des temps où ils vivent et de s'y consacrer », il se demande: \& Avons-nous le coeur assez grand? Tout est là. Il y a devant l'évolution actuelle au moins une attitude radicalement absurde; c'est le conservatisme. Croire que \& tout va se tasser» alors que l'évolution ne fait que 66 